\title{
Hastane Beslenme Hizmetlerinde Hasta Memnuniyeti
}

\author{
Patients Satisfaction in Hospital Food Services
}

\author{
Ali Emrah Blyıklıํㅗ Saniye Bilici ${ }^{2}$
}

Geliş tarihi/Received: 02.10.2018 • Kabul tarihi/Accepted: 17.03.2019

\section{ÖZET}

Sağlık hizmetlerinde kalite şartlarının en önemlilerinden biri hasta memnuniyetinin sağlanmasıdır. Hasta memnuniyeti birçok etmenden etkilenebilmektedir. Hastanelerde yatan hastalara verilen beslenme hizmetleri hasta memnuniyetindeki en önemli bileşenlerden birini oluşturmaktadır. Bu çalışmada, hastaların hastane beslenme hizmetlerinden memnuniyet durumunun değerlendirildiği çalışmalar derlenmiştir. Yapılan literatür taraması sonucunda hastane beslenme hizmetleri, besin kalitesi, menü kalitesi, yemek servis kalitesi, personel hizmet kalitesi, atmosfer kalitesi ve diyetisyen ilgisi alt boyutları altında incelenmiştir. Yatan hastaların beslenme hizmetlerinden memnuniyetini etkileyen etmenler daha çok besin kalitesi ve menü kalitesi alt boyutlarında bulunmaktadır. Hastane beslenme hizmetlerine duyulan memnuniyeti arttırmak için alt boyutlarının tümünü kapsayan bir kılavuz geliştirilmesi sektöre önemli bir kazanç sağlayacaktır.

Anahtar kelimeler: Sağllkta kalite, hasta memnuniyeti, beslenme hizmetleri

\begin{abstract}
One of the most important quality conditions in health services is to provide patient satisfaction. Patient satisfaction could be affected from many factors. Food services provided to hospitalized patients constitute one of the most important components of patient satisfaction. In this study, the studies evaluating patients' satisfaction with hospital food services were compiled. As the result of the literature review, hospital food services; food quality, menu quality, food service quality, personnel service quality, atmosphere quality and dietitian interest were examined under the sub-dimensions. Factors affecting the satisfaction of inpatient services of inpatient patients are mostly in food quality and menu quality sub-dimension. Developing a guideline covering all of the sub-dimensions to increase satisfaction with hospital nutrition services will provide a significant benefit to the sector.
\end{abstract}

Keywords: Quality in health, patient satisfaction, nutrition services

1. ̇letişim/Correspondence: Selçuk Üniversitesi, Akşehir Kadir Yallagöz Sağllk Yüksekokulu, Beslenme ve Diyetetik Bölümü, Konya, Türkiye

-E-posta: dytemrahbykl@hotmail.com

(ㄱ) https://orcid.org/0000-0003-2254-2348
2. Gazi Üniversitesi, Sağlık Bilimleri Fakültesi, Beslenme ve Diyetetik Bölümü, Ankara, Türkiye

৫ https://orcid.org/0000-0002-1235-0329 


\section{GíRIŞ}

Sağlık hizmetleri, bireylerin yaşam kalitesini ve mutluluğunu doğrudan etkilemektedir. Sağlık hizmetlerinde kalite düzeyi ise ülkelerin gelişmişlik düzeyinin bir göstergesi olarak kabul edilmektedir. Sağllk hizmetlerinde kalite, sağllk hizmetinin hem bilimsel norm ve standartlara hem de bireylerin beklentilerine uygun şekilde sunulması anlamına gelmektedir (1).

Sağllk Hizmetleri Genel Müdürlüğü tarafından yayınlanan Sağlıkta Kalite Standartları (SKS) rehberinde hastanelerin sundukları hizmetlerin bazı hedeflere ulaşması gerektiği belirtilmektedir. $\mathrm{Bu}$ hedefler arasında yer alan "Hasta Odaklılık" kavramı, hastanelerde sunulan tüm hizmetlerde hastalarm istekleri, gereksinmeleri, beklentileri ve değerleri dikkate alınarak, teşhiste, tedavi sürecinde ve bakım hizmetlerinde aktif katılımlarının sağlanmasıdır” şeklinde tanımlanmaktadır (2). Bu doğrultuda, hizmet kalitesinin en önemli göstergelerinden biri olan "hasta memnuniyeti” kavramı daha çok önem kazanmaya başlamıştır (3).

Tıbbi hizmetler dışındaki diğer hizmetlerin hasta memnuniyeti odaklı sunulmasını kapsayan sağlık otelciliği ile sağlık hizmetleri kalitesi yanında, tıbbi hizmetleri destekleyen ve hasta memnuniyetinde büyük önemi bulunan otelcilik hizmetlerinin de performansının artırılması sağlanmaktadır. Hastanelerde sunulan sağlık otelciliği, temizlik, yemek, hasta karşılama, kayıt ve güvenlik ile ilgili destek hizmetlerini kapsamaktadır (4). Yapılan çeşitli çalışmalar, hastanelerde verilen beslenme/yemek hizmetlerinin yatan hastaların genel memnuniyetini etkileyen en önemli etmenlerden biri olduğunu ortaya koymaktadır (5-7).

Hastanede beslenme hizmeti alan hasta, personel ve hasta yakınlarının beslenme hizmetlerinden memnuniyetsizlikleri besin tüketiminde azalmaya neden olarak besin, enerji ve işgücünde israflara yol açmaktadır. Bu durum hastanelerde beslenme hizmetleri yönetimine gereken önemin verilmesi zorunluluğunu doğurmaktadır (8).
$\mathrm{Bu}$ çalışmada, hastaların hastane beslenme hizmetlerinden memnuniyetini etkileyen çeşitli alt boyutların derlenmesi amaçlanmıştır.

\section{Hastane Beslenme Hizmetlerinin Önemi ve Özellikleri}

Hastalar için hastaneye yatıştan taburcu olma sürecine kadar beslenme durumunun izlenmesi hayati önem taşımaktadır. Yetersiz beslenen hastalarda hastane enfeksiyon riski artmakta, iyileşme süresi gecikmekte ve hastanede kalış süresi uzamaktadır. Ayrıca bu hastalarda tedavi maliyeti yükselmekte, mortalite ve morbidite riski de artmaktadır $(9,10)$. Çeşitli ülkelerde yapılan çalışmalarda hastanelerde yatan hastaların \%20-60'ında malnütrisyon görülebilmekte ve malnütrisyon ile ilişkili hastalıklar da önemli sorun olarak görülmektedir (11,12). Ülkemizde hastanelerde yapılan çalışmalarda malnütrisyon prevalansı \%15-29.8 olarak saptanmıştır $(13,14)$. Hastanın hastanede yatışında ve yatış yaptığı süre içinde, beslenme durumunun tanımlanmaması ve izlenmemesi sonucunda, hastanın tedavi sürecinden ve komplikasyonlardan olumsuz etkilenmesi, tetkikler ve tedavi nedeniyle düzenli beslenememesi/ öğün zamanını geçirmesi, psikolojik durumu ve hastalığıyla ilgili kaygıları, hastanede kalış süresinin uzaması, beslenme konusunda bilinçli olmaması/ bilinçlendirilmemesi, hastane yemeklerine karşı önyargılı olması ve hastaların diyetisyene yönlendirilmesindeki gecikmeler gibi nedenlerle malnütrisyonun gelişebileceği bildirilmektedir (15). Kowanko et al. (16) yatan hastaların beslenme durumunu değerlendirmişlerdir. Hastaların üçte birinin hastane yemeklerinin sadece \%50'sini tükettiklerini ve bunun sonucunda hastalarda önemli miktarda besin ögesi gereksinimlerinin karşılanamadığını ve malnütrisyon geliştiğini belirlemişlerdir. Beslenme hizmetleri ve hastanede kalış süresinin değerlendirildiği bir çalışmada ise hastanede kalış süresi uzun olan hastaların hastanede kalış süresi kısa olan hastalara göre besin kalitesine daha çok önem verdikleri belirlenmiştir (17). Şahin 
ve arkadaşları (18) ile Stanga et al. (19) yaptıkları çalışmada da hastanede kalış süresinin uzaması ile hastane yemeklerinden ve beslenme hizmetlerinden memnuniyet düzeyinin azaldığı gösterilmiştir.

Hastane beslenme hizmetlerinde hastaların beslenme durumlarının değerlendirilmesinin yanı sıra verilen yemek hizmetleri ile bireylerin fizyolojik, psikolojik ve sosyal gereksinimlerinin karşılanması hedeflenmektedir (15). Hastane beslenme hizmetleri bir zincir şeklinde ve her bir süreç birbiri ile etkileşim içerinde yürütülmektedir (Şekil 1) (20,21). Bu zincirde yer alan herhangi bir süreçteki aksaklıklar ve/veya hatalar hastanin beslenme durumunu etkilemekte ve bu durum hasta memnuniyetine de olumsuz yansımaktadır.

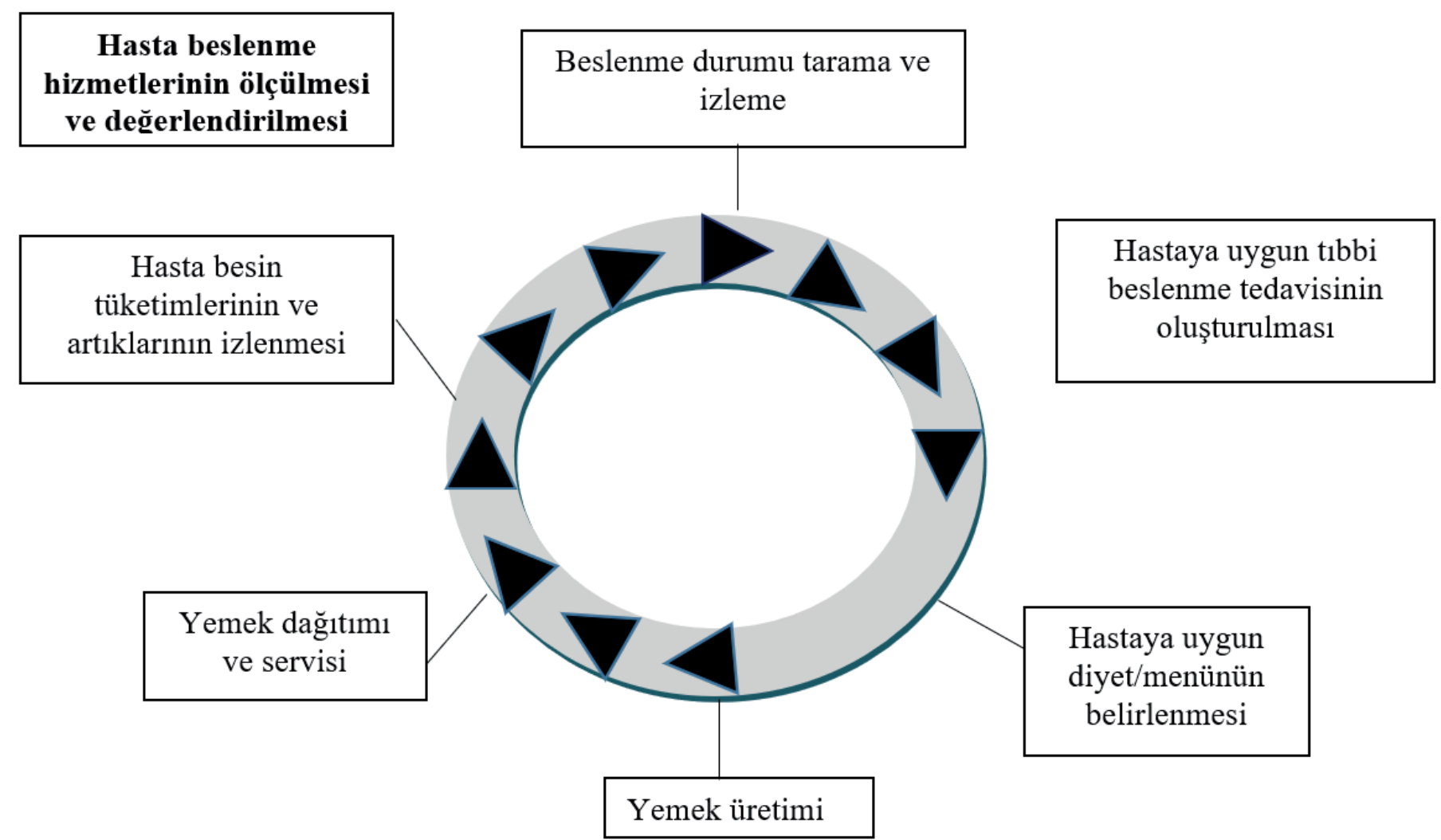

Şekil 1. Beslenme zinciri (20 ve 21 nolu kaynaklardan uyarlanmıştır)

\section{Hastane Beslenme Hizmetlerinin Alt Boyutları}

Hastane beslenme hizmetlerinden duyulan memnuniyeti belirlemek için hasta beklentilerini bilmek gerekir. Beklentilerin karşlanıp, memnuniyetin artırılması hastane beslenme hizmetlerinde kalitenin geliştirilmesi için önemli katkılar sağlamaktadır (22). Yapılan çeşitli çalışmalar sonucunda hastane beslenme hizmetlerinden memnuniyeti etkileyen alt boyutlar besin, personel, yemek servisi ve fiziki koşullar üzerine odaklanmıştır (22-24). Bu makalede ise alt boyutlar besin kalitesi, menü kalitesi, yemek servis kalitesi, personel hizmet kalitesi, atmosfer kalitesi ve diyetisyen ilgisi başlıkları altında incelenmiştir.

Besin kalitesi: Besin kalitesi, öncelikle kullanılan hammaddenin nitelik ve niceliğine bağlıdır. Bunun yanı sıra besin kalitesi yemeğin yapılmasında kullanılan pişirme yönteminin doğru seçimine, tüm süreçlerde besin değerinin korunumunun sağlanmasına, yemeğin organoleptik özelliklerine de bağlıdır (25). Genel olarak yemeğin kalitesini içine konan yiyeceklerin kalitesi, besin değeri, lezzeti, görünüşü, kullanılan su kalitesi ve miktarı, servis 
edilen yemeklerin sıcaklığı ve miktarı etkilemektedir (26). Birçok çalışma sonucuna göre hastane beslenme hizmetlerine karşı duyulan memnuniyeti en iyi açıklayan alt boyut besin kalitesi olarak belirlenmiştir $(23,24)$. Bir başka çalışmada da hastaların beslenme servisinden memnuniyetini geliştirmek için hedeflenecek en önemli boyutun besin kalitesi olduğu belirtilmiştir (25).

Yemeğin içine konan yiyeceklerin kalitesi: Bir yiyeceğin kalitesi genel olarak ölçüsü, şekli, sağlamlığı, doğal rengi, özel kıvamı, içyapısı, kokusu ve lezzeti ile tanımlanır (26).

Yemeğin besin değeri: Yemeğin besin değeri, içerisinde kullanılan besinlerle ilgilidir. Burada önemli olan kullanılan besinlerin, hazırlama ve pişirme sırasında besin değerlerini kaybetmemelerini sağlayarak ve sindirilmelerini kolaylaştırarak daha yararlı hale getirmek, sağlık için zararlı bir madde oluşumunu önlemektir (26).

Yemeğin lezzeti ve görünüşü: Yemeğin lezzet ve görünüşüne, renk, şekil, kıvam ve kokusu gibi organoleptik özellikler etki etmektedir (26). Bir üniversitenin yemekhanesinde yemek yiyen kişiler ile yapılan çalışmada, memnuniyet düzeyinin artırılması için yemeklerin organoleptik özelliklerine daha fazla dikkat edilmesi belirtilmektedir (27).

Yemeklere konulan suyun kalitesi ve miktarl: Yemek pişirmedekullanılansu,uygunkaynaktansağlanmazsa içerdiği klor kokusu ve yüksek mineralleri nedeniyle yemeğin lezzeti etkilenmektedir. Mümkün olduğu kadar yemeklerde içme suyu kullanılmalı ya da musluklardan akan suların içilebilir sular olduğundan emin olunmalıdır (26). Yine, besin güvenliği için beş anahtar ilkesinden biri de besinlerin hazırlanmasında kullanılan temiz su gerekliliğidir (28). Suyun kalitesi kadar yemeğe konulan miktarı yemek kalitesine etki eder. Yemeğe konulacak su miktarı ısı ayarlaması ile paralel gider. Isı gereğinden yüksek tutulursa fazla su kaybi olur (26).
Yemeğin sıcaklığı: Yemek kalitesini etkileyen en önemli etmenlerden birisi de yemeklerin servis sıcaklığının uygunluğudur (26). Literatürde yapılan çalışmalar incelendiğinde, hastane beslenme hizmetlerinden en fazla memnuniyetsizlik yemeklerin yeterince sicak servis edilmemesinden kaynaklanmaktadır (18,29). Sıcak tutulacak besinlerin sicaklığı $65^{\circ} \mathrm{C}$ düzeyinin altına düşmemelidir ve yemekler bu sicaklıkta 2 saatten daha uzun süre tutulmamalıdır (30). Çorbalar için bu $70^{\circ} \mathrm{C}$ 'dir (26). Yemek piştikten sonra bekletilirse ve bekleme ortamı uygun olmazsa kalitesi bozulur. Ayrica uzun süre bekletilen yemeklerde besin güvenliğini tehdit eden çeşitli patojen mikroorganizmalar (Clostridium perfringens, Bacillus cereus vb.) oluşabilir. Yemeklerin servise kadar sunum sıcaklıklarına göre soğutuculu dolaplarda $\left(+4^{\circ} \mathrm{C}\right)$ veya sıcak bekletme üniteleri/Benmari'de $\left(65^{\circ} \mathrm{C}\right.$ ve üzerinde) bekletilmesi önemlidir $(26,30)$.

Yemeğin temizliği: Besin değeri yüksek ve lezzetli bir yemeğin içerisinde yabancı bir madde çıkması kişiyi huzursuz kılmakta, yemeğin tüketilmemesi nedeniyle ekonomik kayba neden olmaktadır. Yemeğin temizliği gözle görülen maddeler dışında mikrobiyolojik bakımdan da temiz olması ile ölçülür (26). Besin güvenliğinin sağlanmasında genel temizlik ve kişisel hijyen koşulları, pişmiş besinler ile çiğ besinlerin ayrılması, uygun sıcaklık ve sürede pişirme, besinlerin uygun sicaklıklarda saklanması, temiz su ve temiz malzeme kullanımı önemlidir (28).

Menü kalitesi: Menü, Toplu Beslenme Sistemlerinde servis edilen yemeklerin listesi olup, tüketiciyle kuruluşların beslenme servisi örgütleri arasındaki iletişimi sağlayan önemli bir araçtır. Daha ayrıntılı bir tanımla, menü tüketicilerin gereksinim ve/veya talepleri doğrultusunda, tasarlanan yiyecek ve içeceklerin bir planıdır. Genellikle menü planlama ve geliştirme en az anlaşılan ve en çok ihmal edilen konudur. İyi planlanmış menüler tüketicilerin fizyolojik, sosyal ve psikolojik gereksinimlerini karşılar ve toplu beslenme sistemi yönetimini başarılı kllar. Menü planlamayı etkileyen en önemli etmenler beslenme servisi örgütüne ve tüketici/müşteriye ait etmenlerdir. Beslenme servisi örgütüne ait etmenler, 
beslenme servisi örgütünün şekli ve amacı, bütçesi, piyasa koşulları, fiziksel imkânlar, araç-gereçler, servis şekli ve personel durumunu kapsamaktadır. Tüketici/müşteriye ait etmenlerse, menü planlanan grubun besin gereksinimleri, beslenme alışkanlıkları ve yemek tercihleri gibi etmenlerdir (26). Menüler planlanırken multidisipliner (yönetici diyetisyen, beslenme hizmetleri çalışanları ve diğer sağlık personelleri) bir takım oluşturulmalıdır. Hastaların enerji ve besin ögeleri gereksinimleri belirlenmeli, özellikle uzun süre hastanede yatan hastalar için menü monotonluğunu önlemeye yönelik esnek menü alternatifleri geliştirilmelidir (31).

Grubun besin gereksinmeleri: Besin gereksinmeleri yaş, cinsiyet ve aktiviteye göre belirlenir. Yemek listesi planlanırken bu gereksinmeler göz önüne alınır (26). İskoçya hastane beslenme hizmetleri rehberinde ise beslenme durumu riskli olan yetişkin hastaların 2250-2625 kkal/gün, beslenme durumu iyi olan yetişkin hastaların ise 1800-2550 kkal/gün gereksinmesinin hastane menüleriyle sağlanması gerektiği belirtilmektedir (31). Ayrıca bu rehberde 5 besin grubunun da menülerde dengeli olarak bulunması gerektiği belirtilmektedir. Bunlar, ekmek, diğer tahıllar ve patates, sebze ve meyveler, süt ve süt ürünleri, et, balık ve alternatifleri, yağ içeren besinler ve şeker içeren besinlerdir (31).

Grubun beslenme alışkanllkları ve yemek tercihleri: Yemek alışkanlıkları, yaş, eğitim, sosyo-kültürel yapı, gelenek ve görenekle ilgilidir ve küçük yaşlarda gelişmektedir. Kişiden kişiye değişebilen çeşitli alışkanlıklar olabilmesine karşılık, bireyler grup içerisinde, belirli yiyeceklere belirli tepkiler gösterebilmektedir. Çok sayıda kişisel ayrıcalığı olanlar bile grup fikrine uyabilmektedir. Kurum beslenme servislerinde yemek yiyen bireylerin genel olarak fikirleri alınarak, yemek listeleri buna göre yapılırsa memnuniyet daha yüksek olmaktadır (26).

Fiziksel özellikler: Depolama, hazırlama, pişirme ve servis için gerekli araç-gereçler ve mutfak planı yemek planlamaya etki eden fiziksel özelliklerdendir. Mutfak iş akımına uygun planlanmamışsa, personelin rahat çalışmasına engel olacak şekilde dar ise ve gereken işlemler için yeterli araç-gereç yoksa müşteri memnuniyeti yaratacak başarılı bir yemek listesi hazırlamak kolay değildir (26).

Personel durumu: Personel sayısı, yeteneği ve bilgisi yemek planını büyük ölçüde etkiler. Bütçesi sınırlı kurumlarda kaliteli personel çalıştırmak zordur. $\mathrm{Bu}$ durumda yemek listesini planlayan kişi personel sayısı ve yeteneğine uygun yemek listesi hazırlamakta zorlanir (26).

Bütçe durumu: Yemek planı yapılmadan önce kurumun beslenme servisine ayırdığı bütçe bilinmelidir. Beslenme servisi bütçesini yiyeceğe, personele, araç-gerece ve yakıta harcanan para oluşturur. Bütçe olanakları kısıtlı olduğunda iyi kalitede mal almak, kaliteli personel çalıştırmak, yeterli araç ve gereç almak zorlaşmaktadır (26).

Servis tipi: Yemek listesi, servisin tabldot, seçmeli ya da oda tipi gibi servis tipine bağlı olarak üç, dört ya da daha fazla çeşit barındıran bir yapıda planlanabilir (26). Hastanelerin beslenme hizmetleri bölümünde yeni geliştirilmeye çalışılan bir yöntem hastaların “istediği besinden, istediği zaman yeme” arzusuna cevap verebilmek için yapılmış olan otel tipi hizmet yaklaşımıdır. Bunu sağlamak için hastaların, tıbbi beslenme tedavilerine bağlı kalarak elektronik menülerden ara öğünler de dahil olmak üzere seçim yapabilmeleri üzerinde çalışılmaktadır. Bu teknoloji ile hastaların gereksinmelerine daha iyi cevap verilebileceği, servisteki yanlışlıkların önleneceği, besin tüketimi artarken artıkların azaltılacağı vurgulanmaktadır. Ayrıca bu sistemle getirilen en önemli yeniliklerden birisi de menüdeki yemeklerin içeriği ve alerjen bilgisinin yer almasıdır (32,33). Avustralya'da özel bir hastanede yapılan bir çalışmada oda servisi yönteminin geleneksel yönteme göre hasta memnuniyetini artırdığı, besin alımını geliştirdiği ve tabak artıklarını azalttığı belirlenmiştir (34). Başka bir çalışmada da seçmeli menü kullanılmasıyla hastaların beslenme hizmetlerinden memnuniyet düzeyleri \%5 artırılmıştır (35). 
Yemeği hazırlama ve pişirme yöntemi: Hazırlığı uzun süren yemekler menüde bir araya konulursa aksamalara neden olur. Ayrıca yeterli firın ya da kızartma tenceresi bulunmadiğında sorun yaratacağından, her ikisi de firınlama ya da kızartma gerektiren yemekler aynı menüde kullanılmamalıdır (26).

Coğrafi özellik, iklim ve mevsimler: Kurumlarda bulundukları bölgenin özelliğine göre yiyeceklere ulaşma olanakları değişmektedir ve yemek listesi hazırlanırken bu duruma dikkat edilmelidir. İklim şartları kişinin besin gereksinmeleri etki eder. Soğuk havalarda sıcak ve enerji içeriği daha yüksek ve sıcak havalarda ise enerji içeriği daha düşük ve soğuk yemekler gerektiği bilinen bir husustur. Yiyecek bulma olanağı mevsimlere göre ayrıcalık gösterir. Seracılığın gelişimine bağlı olarak bu durum her ne kadar değişmişse de bu tür yetişen ürün pahalılığ 1 nedeniyle tercih edilmez (26).

Renk, kıvam, tat ve şekil uyumu: Menü planlama temel ilkeleri doğrultusunda aynı öğündeki menü örüntüsünde yer alan yemeklerde renk, kıvam, şekil, lezzet, tat, görünüm, hazırlama ve pişirme yöntemi, içerik ve sunum şekli açısından çeşitlilik sağlanmalıdır. Sunum kalitesini arttırmak için doğal meyve ve sebzeler kullanılmalıdır (36).

Yemek servis kalitesi: Toplu beslenme servisi yapılan kurumlarda görevli beslenme servisi yöneticileri, yemek dağıtımını gürültüsüz, düzenli, saatinde ve tüketiciye zevkli bir şekilde sunulmasını sağlamakla yükümlüdürler (37). Yapılan araştırmalarda hasta şikayetinin genellikle yemeğin servis kalitesi ve sunumu ile ilgili olduğu görülmektedir. Hastalar yemekleri tatmadan önce görüntüsü ve sunumuna bakarak yorum yapma eğilimindedirler. Bu nedenle, hastanelerin de son zamanlarda otel servisi sistemine dönmeye başlaması ile birlikte yemeklerin sunumları ve görüntüsüne ayrıca önem verilmeye başlanmıştır. Hasta yemeklerini yapan aşçlların turizm sektöründe çalışma geçmişinin olması da yemeklerin sunum ve görünümdeki öneminin üzerinde durulmasını sağlamıştır $(38,39)$. Bir çalışmada, hastanede yemek hizmetlerinin özel bir şirket tarafından verilmesi ve yemeklerin tabldot şeklinde değil de porselen tabaklarda servis edilmesinin yemeklerin sunum şekliyle ilgili olarak memnuniyet durumunu olumlu etkilediği belirlenmiştir (40).

Personel hizmet kalitesi: Yemek hizmetlerinin bir boyutu da müşteri ve çalışan arasında iletişimin geçtiği bir süreci ifade etmektedir ve bu süreç içerisinde servis personelinin davranışları, tutumu, kıyafeti, servis şekli müşterinin hizmet kalitesini algılamasında etkili olmaktadır.Servispersonelininhizmetkalitesi,müşteri memnuniyetini etkilemektedir (37). Toplu beslenme hizmetlerinde çalışan personelin iletişim becerisi ve saygı, nezaket, sıcaklık, empati ve yardımseverlik gibi davranışları müşteri memnuniyetinin önemli bir bölümünü oluşturmaktadır. Yemek sektöründe servis personelinin iyi davranışlar göstermesi güler yüzlü, ilgili olması ve servis yapmaya istekli olması, mesleki becerisi düşük olsa bile memnuniyeti artıran bir etmendir. Herhangi bir yerde yemek yiyen kişi saygll, insancıl, sevecen kişilerin kendisine servis yapmasını istemektedir (37). Servis personelinin sunum şekli yüksek kaliteli bir servis için gereklidir. $\mathrm{Bu}$ nedenle hizmet içi eğitimle bilgilendirilmiş servis personelinin çalıştırılması önemlidir (41).

Atmosfer kalitesi: Günümüzde toplu beslenme hizmetlerinde müşteriler sadece iyi yemekle değil, iyi bir hizmet ve keyifli bir yemek ortamiyla da ilgilenmektedir. İnsanlar yeme amacıyla herhangi bir restoran veya kurum yemekhanesine gittiğinde yemek öncesinde, sırasında ve sonrasında bilinçli ya da bilinçsiz olarak fiziksel çevreyi hissetmektedir. $\mathrm{Bu}$ nedenle içinde bulundukları ortamın, sunulan yiyeceğin ve hizmetin kabul edilebilir nitelikte olması hoş bir fiziksel çevrede sunulması önem arz etmektedir. $\mathrm{Bu}$ beklentinin büyük ölçüde karşılanması genel müşteri memnuniyeti ve sonraki müşteri davranışı derecesini belirlemektedir (37). Hastaların bulundukları fiziksel çevreden memnun olma durumları iyileşme zamanı ve hasta morali üzerine olumlu etki göstermektedir (42). Hastanelerde yemek tüketilecek atmosferin planlanmasında etkili olabilecek etmenler, bireylerin görme, dokunma, 
işitme, koklama, sıcaklık ve hareket alanı aracılığıyla algıladıklarına bağlıdır. Tüm bu algılardaki uygunsuzluklar hastanın beslenme hizmetine yönelik tepkisine yansımaktadır. Görme, görsel alan, aydınlatma ve renklerin algisını, dokunma, yatak konforu ve kullanılan kumaşın algısını, işitme, gürültü düzeyleri, konuşma ve yan duvarlardan gelen seslerinin algısını, koklama, yemek aroması, vücut kokusu ve temizlenmiş malzemenin algısını, sıcaklık, hava sıcaklığı, bağıl nem, vücut sıcaklığı ve pişmiş besinlerin sıcaklığının algısını ve hareket alanı, diğer hastalar ve personellerin hareket alanı algısını ifade etmektedir (43). Müşteri memnuniyetinde fiziksel ve sosyal çevre çoğu zaman servisin önüne geçmektedir (37). Yapılan bir çalışmada, dışarıda yemek yiyen kişilerin yemek yedikleri yerin atmosferi içerisinde en çok aydınlatma ve ambiyansa dikkat ettiği, servis personelinin restoran atmosferi içerisinde değerlendirmeye alınmadığı saptanmıştır. Çalışma sonucunda, davranışı etkileyen fiziksel çevrenin önemi doğrulanmıştır (44). Belirli koşullar altında arka plan müziğinin bile ruh halini etkileyerek ve atmosferi geliştirerek memnuniyeti arttırdığı bildirilmektedir (45).

Diyetisyen ilgisi: Diyetisyen, modern sağlık bakım takımının elzem bir üyesidir. Dünya Sağlık Örgütü Uluslararası Meslek Standartlarını temel alarak sağlık çalışanlarının uluslararası sınıflamasını yapmıştır. Bu sınıflamada diyetisyeni şöyle tanımlamıştır, "İnsan sağlığı üzerine besinler ve beslenmenin etkisini değerlendiren, planlayan ve beslenme programlarını yerine getiren meslek üyesidir. Diyetisyenler bireyler ve toplum için beslenme durumunu geliştirmek amacıyla araştırmalar, ölçümler ve eğitimler yapabilirler.” Ayrıca burada diyetisyen tanıma ek olarak diyetisyenlerin çalışma alanlarına yer verilmiş ve klinik diyetisyenlik de çalışma alanlarından biri olarak belirtilmiştir (46). Hastane diyetleri ile ilgili konular genel hasta memnuniyetine önemli etkide bulunur. Diyetisyenler, hasta memnuniyet verilerini diyet hizmetlerinin değerlendirilmesinde somut ve ölçülebilir bir sonuç olarak kullanabilir. Bu şekilde, diyet hizmetlerinin de hastalar için önemli olduğu gösterilebilir. Böylece, diyet hizmetlerinin hasta beklentilerini karşılayıp karşılamadığının doğru bir şekilde değerlendirilmesi sağlanabilir (47).

\section{SONUÇ VE ÖNERİLER}

Yatan hastaların beslenme hizmetlerinden memnuniyetini azaltan en önemli etkenlerin başında hastalara sunulan yemeklerin uygun sicaklıklarda servis edilmemesi ve yemeklerin lezzetinin yetersizliği gelmektedir. Bu doğrultuda teknolojik gelişmelerin izlemiyle uygun araç-gerecin seçimi, yemek sıcaklıklarının Gıda Güvenliği Yönetim Sistemleri kapsamında sürekli izlemi, yemeklerde lezzetin ve çeşitliliğin arttırılmasına yönelik standart tarifelerde inovasyon çalışmalarının yürütülmesi son derece önemlidir. Özellikle kamu hastanelerinde uygulanacak hastane yemek hizmetleristandartlarına yönelik bir kılavuz geliştirilmesi de sektöre önemli kazanç sağlayacaktır. Hastanelerde beslenme hizmetlerinin yöneticisi ve hastaların beslenme durumlarından sorumlu olan diyetisyenlerin yeniliğe ve gelişime açık bir tutum sergilemesi beslenme hizmetlerine yönelik memnuniyetin artırılması bakımından önemlidir.

Çıkar çatışması - Conflict of interest: Yazarlar çıkar çatışması olmadığın beyan ederler. - The authors declare that they have no conflict of interest.

\section{KAYNAKLAR}

1. Kömürcü N, Durmaz A, Bayram N, Koyucu RG, Karaman ÖE, Toker E. Sağlık hizmetlerinde kalite standartları ve modelleri. Sağlıkta Performans ve Kalite Dergisi 2014;7:95-114.

2. Sağlık Hizmetleri Genel Müdürlüğü. Sağlıkta Kalite Standartları Hastane. Ankara, 2. Baskı. Sağlık Hizmetleri Genel Müdürlüğü; 2016. s. 21.

3. Halil Z, Tarım M. Hasta memnuniyeti: kamu hastaneleri üzerine bir alan araştırması. Sosyal Siyaset Konferansları Dergisi 2010;59:1-24.

4. Türkiye Kamu Hastaneleri Kurumu. Hizmet Sunum Rehberi. Tıbbi Hizmetler Kurum Başkan Yardımcılığı Sağlık Bakım ve Hasta Hizmetleri Daire Başkanlığı. 2014. Erişim: http://www.tkhk.gov.tr/ Dosyalar/82d3f45d0cd847979aa4fc9715bfd7c7.pdf Erişim tarihi: 20 Haziran 2018. 
5. Barr JK, Giannotti TE, Sofaer S, Duquette CE, Waters WJ, Petrillo MK. Using public reports of patient satisfaction for hospital quality improvement. Health Serv Res. 2006; 41(3):663-82.

6. Demirel ET, Derin N. Sağlık hizmetlerinde kalitenin göstergesi olan hasta memnuniyetine yönelik ölçek geliştirme çalışması. The Journal of Academic Social Science Studies 2013;6(2):1111-30.

7. Büber $R$, Başer $H$. Sağlık işletmelerinde müşteri memnuniyeti: vakıf üniversitesi hastanesinde bir uygulama. Sosyal ve Beşeri Bilimler Dergisi 2012;4(1):265-74.

8. Bıyıklı AE, Aktaş N. The determination of the knowledge and practice concerning food safety for cooks working in hospital kitchens: Konya city centre sample. Uluslararası Hakemli Beslenme Araştırmaları Dergisi 2014;1(1):1-11.

9. Gamaletsou M, Poulia K-A, Karageorgou D, Yannakoulia M, Ziakas P, Zampelas A, Sipsas N. Nutritional risk as predictor for healthcare-associated infection among hospitalized elderly patients in the acute care setting. J Hosp Infect. 2012;80(2):168-72.

10. White JV, Guenter P, Jensen G, Malone A, Schofield M. Academy Malnutrition Work Group; ASPEN Malnutrition task force; ASPEN Board of Directors. Consensus statement: Academy of Nutrition and Dietetics and American Society for Parenteral and Enteral Nutrition: characteristics recommended for the identification and documentation of adult malnutrition (undernutrition). J Parenter Enteral Nutr. 2012;36(3):275-83.

11. Waitzberg DL, Caiaffa WT, Correia MIT. Hospital malnutrition: the Brazilian national survey(IBRANUTRI): a study of 4000 patients. Nutrition 2001;17(7):573-80.

12. Jensen GL, Mirtallo J, Compher C, Dhaliwal R, Forbes A, Grijalba RF, Hardy G, Kondrup J, Labadarios D, Nyulasi I. Adult starvation and disease-related malnutrition: a proposal for etiology-based diagnosis in the clinical practice setting from the International Consensus Guideline Committee. Clin Nutr. 2010;29(2):151-53.

13. Korfalı G, Gündoğdu H, Aydıntuğ S, Bahar M, Besler T, Moral AR, Oğuz M, Sakarya M, Uyar M, Kılıçturgay S. Nutritional risk of hospitalized patients in Turkey. Clin Nutr. 2009;28(5):533-37.

14. Nursal TZ, Noyan T, Atalay BG, Köz N, Karakayali H. Simple two-part tool for screening of malnutrition. Nutrition 2005; 21(6):659-65.

15. Akbulut G, Yllmaz B. Hastane malnütrisyonunun önlenmesinde yemek hizmetlerinin rolü. Turkiye Klinikleri J Nutr Diet-Special Topics 2016;2(3):33-9.

16. Kowanko I, Simon S, Wood J. Energy and nutrient intake of patients in acute care. J Clin Nurs. 2001; 10(1): 51-7.

17. Tranter MA, Gregoire MB, Fullam FA, Lafferty LJ. Can patient-written comments help explain patient satisfaction with food quality? J Am Diet Assoc. 2009;109(12):2068-72.

18. Sahin B, Demir C, Celik Y, Teke AK. Factors affecting satisfaction level with the food services in a military hospital. J Med Syst. 2006;30(5):381-7.

19. Stanga Z, Zurflüh Y, Roselli M, Sterchi A, Tanner B, Knecht G. Hospital food: a survey of patients' perceptions. Clin Nutr. 2003;22(3):241-6.

20. Hartwell HJ, Edwards JS, Symonds C. Foodservice in hospital: development of a theoretical model for patient experience and satisfaction using one hospital in the UK National Health Service as a case study. J Foodservice 2006; 17(5-6):226-38.

21. Beck AM, Balkn U, Fürst P, Hasunen K, Jones L, Keller U, Melchior J, Mikkelsen B E, Schauder P, Sivonen L. Food and nutritional care in hospitals: how to prevent undernutrition-report and guidelines from the Council of Europe. Clin Nutr. 2001;20(5):455-60.

22. Capra S, Wright O, Sardie M, Bauer J, Askew D. The acute hospital foodservice patient satisfaction questionnaire: The development of a valid and reliable tool to measure patient satisfaction with acute care hospital foodservices. J Foodservice 2005;16(1-2):1-14.

23. Dubé L, Trudeau E, Bélanger MC. Determining the complexity of patient satisfaction with foodservices. J Am Diet Assoc. 1994;94(4):394-401.

24. Wright OR, Connelly LB, Capra S. Consumer evaluation of hospital foodservice quality: an empirical investigation. Int J Health Care Qual Assur. 2006;19(2):181-94.

25. Lau C, Gregoire MB. Quality ratings of a hospital foodservice department by inpatients and postdischarge patients. J Acad Nutr Diet, 1998;98(11):1303-7.

26. Merdol TK. Toplu Beslenme Servisi (TBS) Sağlıklı Yönetim Rehberi. 2. Baskı. Ankara: Hatiboğlu Yayınevi; 2017.

27. Çelik M. Müşteri memnuniyeti ve hizmet kalitesi üzerine Adıyaman Üniversitesi yemekhanesi'nde bir uygulama. Adıyaman Üniversitesi Sosyal Bilimler Enstitüsü Dergisi 2012;(10):29-54.

28. Besler H, Rakıcıoğlu N, Ayaz A, Büyüktuncer-Demirel Z, Gökmen-Özel H. Türkiye’ye Özgü Beslenme Rehberi. Ankara: Merdiven Reklam Tanıtım; 2015.

29. Zahid M, Zaidi SK, Naqvi S, Iqbal S, Maqsood B, Iqbal A. Survey of patients'perception of hospital food services at afic-nihd rawalpindi. Pak Armed Forces Med J 2015;65(Suppl):102-5.

30. Anonim. Toplu Tüketim Yerleri İçin Hijyen Esasları ve İyi Uygulama Kılavuzu. Kılavuz no: 5. Erişim: http://www.webcitation.org/ query? url=h t t p \% 3 A \% 2 F \% 2 Fw w w.tesk.org. tr\%2Ftr\%2Fcalisma\%2Fgida\%2Ftoplutuketimhijyen. pdf Erişim tarihi: 06 Haziran 2018. 
31. Government LCW. All Wales Nutrition and Catering Standards for Food and Fluid Provision for Hospital Inpatients. 2011. Available at: http://www.webcitation. org/query?url=http\%3A\%2F\%2Fwww.wales.nhs.uk\%2 Fsitesplus\%2Fdocuments\%2F862\%2FFOI-077e-15.pdf Accessed June 08, 2018.

32. Government TS. Food in Hospitals National Catering and Nutrition Specification for Food and Fluid Provision in Hospitals in Scotland. Edinburgh: Scottish Government. 2008. Available at: http://www. webcitation.org/query?url=http\%3A\%2F\%2Feresearch. qmu.ac.uk\%2F810\%2F1\%2FeResearch_810.pdf Accessed June 08, 2018.

33. Ongan D. Özel gruplarda menü yönetimi ve denetiminde güncel eğilimler. Turkiye Klinikleri. J Nutr Diet -Special Topics 2016; 2(3): 27-32.

34. McCray S, Maunder K, Krikowa R, MacKenzie-Shalders K. Room service improves nutritional intake and increases patient satisfaction while decreasing food waste and cost. J Acad Nutr Diet 2018;118(2):284-93.

35. Mosqueira C, Harris L. Spoken menu: a menu process catered to the patients food choices and present appetite. J Am Diet Assoc. 1996;96(9):A14.

36. Health GWAD. Nutrition Standards for adult inpatients in WA hospitals. 2012. Available at: http://www.webcitation. org/query?url=http\%3A\%2F\%2Fwww.health.wa.gov. au\%2Fcircularsnew\%2Fattachments\%2F1108.pdf Accessed June 10, 2018.

37. Uçar A. Toplu beslenme hizmetlerinde tüketici memnuniyeti. Turkiye Klinikleri J Nutr Diet J-Special Topics 2016; 2(3):40-6.

38. Ariffin HF, Bibon MF, Abdullah RPSR. Restaurant's atmospheric elements: What the customer wants. Procedia Soc Behav Sci 2012;38:380-7.

39. Zellner DA, Loss CR, Zearfoss J, Remolina S. It tastes as good as it looks! The effect of food presentation on liking for the flavor of food. Appetite 2014;77:31-5.

40. Konca GE, İlhan MN, Bumin MA. Yatarak tedavi gören hastalarin hastane çalışanları ve hastane hizmetlerinden beklentileri ve beklentilerine ilişkin memnuniyet durumlarının değerlendirilmesi. Gazi Tıp Derg. 2006;17(3):42-52.

41. Schneider B, White SS, Paul MC. Linking service climate and customer perceptions of service quality: Tests of a causal model. J Appl Psychol 1998;83(2):150-63.

42. Nguyen N, Leblanc G. Contact personnel, physical environment and the perceived corporate image of intangible services by new clients. International Journal of Service Industry Management 2002;13(3):242-62.

43. Hartwell H. Patient experience, nutritional uptake and satisfaction with hospital food services. [Doctorate Thesis]. Bournemouth University, England; 2004.

44. Han H, Ryu K. The roles of the physical environment, price perception, and customer satisfaction in determining customer loyalty in the restaurant industry. Journal of Hospitality \& Tourism Research 2009;33(4):487-510.

45. Duncan Herrington J, Capella LM. Practical applications of music in service settings. J Serv Mark. 1994;8(3):50-65.

46. WHO. Classifying health workers: Mapping occupations to the international standard classification Available at: http://www.who.int/hrh/statistics/Health_workers_ classification.pdf Accessed June 12, 2018.

47. Peng YL. Patient satisfaction survey as a quality control measure for nutrition counselling services. Available at: http://www.snda.org.sg/downloads/ publications/patient $\% 20$ satisfaction $\% 20$ survey $\% 20$ as $\% 20$ quality $\% 20$ control $\% 20$ measure $\% 20$ for $\% 20$ nutrition $\% 20$ counselling $\% 20$ service_poster.pdf Accessed June 15, 2018. 